\title{
EFECTO DE LAS EXPORTACIONES EN EL CRECIMIENTO ECONÓMICO DE BAJA CALIFORNIA SUR: UNA APLICACIÓN DEL MODELO DE BASE ECONÓMICA Y SU MULTIPLICADOR
}

EFFECTS OF EXPORTS IN THE ECONOMIC GROWTH OF BAJA CALIFORNIA SUR: AN APPLICATION OF THE ECONOMIC BASE MODEL AND MULTIPLIER

\author{
Karol Solís Ávila $\quad$ Crucita Aurora Ken Rodríguez \\ Consultor independiente Universidad de Quintana Roo, México \\ karol.solis@mail.com cruken@uqroo.mx
}

\section{RESUMEN}

Este trabajo intenta explicar el efecto de las exportaciones en las economías locales a través del análisis de desempeño de la economía de Baja California Sur. El objetivo es analizar los efectos de las exportaciones en el crecimiento económico a nivel municipal y aplicar el modelo de base económica y su multiplicador en economías locales. Se emplea como línea teórica el crecimiento económico regional y los sistemas productivos. El análisis evidencia que la economía subbajacaliforniana es competitiva, porque los municipios registran excedentes de producción exportables; están en condiciones de satisfacer la demanda interna, y dependen en menor proporción relativa de las importaciones. Se demuestra que las economías locales presentan potencial para articular sistemas productivos de proveeduría para impulsar su crecimiento. 
Palabras clave: economías locales, crecimiento económico regional, Baja California Sur, modelo de base económica, multiplicador de la base económica, sistemas productivos.

Clasificación JEL: 040

\begin{abstract}
This paper attempts to explain the effect of exports in local economies with the use of the economic performance analysis of the State of Baja California Sur. The objective is to analyze the role of exports on economic growth at the municipal level and apply the economic base model and its multiplier in local economies. Its theoretical background is based on regional economic growth and productive systems. The analysis shows that the Subbajacalifornian economy is competitive, as the municipalities recorded exportable surpluses; proved their ability to meet domestic demand, and demonstrated relatively less dependency on imports. As a result, local economies have potentials to articulate their productive systems, and therefore, boost their growth.
\end{abstract}

Key words: local economies, regional economic growth, Baja California Sur, economic base model, economic base multiplier, productive systems 


\section{INTRODUCCIÓN}

Las transformaciones productivas y los procesos de crecimiento económico han dado lugar a nuevos sistemas productivos que han llevado al aumento y diversificación de la producción, generando diferencias en las capacidades y potencialidades de las economías. En este sentido, es posible decir que "la diversidad de la economía conduce a diferentes sendas de crecimiento para cada región, brindando diferentes etapas y niveles de desarrollo" (Vázquez, 2002:10).

La configuración de sistemas productivos es una estrategia para la permanencia de las unidades de producción cuyo principal objetivo es "mejorar las condiciones económicas y sociales de los entornos territoriales, sobre todo los locales" (Iglesias y Ramírez, 2008:65). De ello la necesidad de detectar eventuales factores de competitividad e interconexiones potenciales entre las diferentes actividades productivas para que impulsen las economías regionales, con el afán de mejorar el posicionamiento en los diferentes mercados y aumentar el empleo y el ingreso en los contextos subregionales, principalmente.

El objetivo del presente trabajo es dual; por un lado, analizar los efectos de las exportaciones en el crecimiento económico de Baja California Sur, considerando sus cinco municipios y, por otro, mostrar las potencialidades locales de este estado utilizando el modelo de base económica y su multiplicador.

\section{REVISIÓN DE LA LITERATURA}

Al partir de que "la imagen resultante de las regiones y las relaciones interregionales es sumamente compleja” (Massey s/f: 44) es posible sostener que

“el funcionamiento de cualquier sistema económico [...], genera efectos previstos y no previstos, notables y no notables, rápidos o lentos, esporádicos o permanentes, en el monto de la producción 
de bienes y servicios, en su distribución, en la generación o asimilación de innovaciones tecnológicas, en los mecanismos y procedimientos de acceso al poder, en el uso de los recursos y en la distribución territorial de la población y la producción" (Boisier, 1993:310).

Por estas razones, se vuelve necesario comprender los fenómenos en el interior de las regiones, con el propósito de ofrecer alternativas de solución a las disparidades regionales a través de intervenciones públicas y privadas más efectivas que impacten de manera positiva, no sólo sobre el crecimiento, sino también en el desarrollo de las regiones. Uno de los fenómenos internos de las regiones es la producción y su intercambio con las regiones colindantes.

Las regiones son sistemas económicos abiertos, "desde el punto de vista de la importancia relativa de la demanda externa como factor de crecimiento regional" (Boisier, 1980:61). Según Polése (1998:149) "la región, a diferencia del territorio nacional, no tiene fronteras en el sentido económico. Los intercambios de bienes y servicios se realizan sin tomar en cuenta las fronteras regionales, sin trabas administrativas". Por lo anterior, no existe registro oficial de los intercambios de bienes y servicios entre las regiones, pero se realizan estimaciones a partir de métodos de análisis regional que nos permiten inferir la exportación y la importación regional. La intensidad de las relaciones de una región con el exterior, como objeto de estudio, utiliza modelos explicativos que nos permiten estudiar su especialización productiva y el intercambio a través del análisis de la base económica regional que le da sustento.

El análisis de la base económica es el modelo más coherente y más generalizado para explicar el nivel de actividad económica de una región. "Este modelo traza una línea de demarcación entre las industrias básicas que permite a la región la entrada de ingresos y las industrias complementarias (actividades no básicas) que resultan de la presencia de las actividades básicas" (Polése, 1998:151-152). A través del análisis de base económica de un municipio, podemos determinar las ramas de actividad que se especializan en el mercado local (sector no básico) y las que se especializan en exportar (sector básico). "Este modelo está sustentado en 
la idea de que una economía local (ciudad-región) para crecer, debe aumentar sus flujos monetarios hacia dentro y la única manera de lograrlo es incrementando las exportaciones" (Torres, 2009:194). Para realizar el análisis se utiliza el valor agregado y/o la mano de obra empleada en las ramas de producción de cada región. El método más común empleado para la determinación de la especialización de los sectores es el coeficiente de localización.

En términos más sencillos, el coeficiente de localización nos permite comparar el nivel del valor de un indicador, en este caso, del valor agregado y/o del empleo de que dispone una actividad en una región dada, respecto al valor del indicador, valor agregado y/o empleo, de la actividad en todo el sistema del territorio. El valor del coeficiente expresa el grado de concentración de la actividad en la región en relación con el territorio de referencia. "Un valor superior a 1 significa una concentración más que proporcional en la región (Polése, 1998:154), lo cual significa que la región está especializada y es exportadora en esa rama de producción”. Es decir, se comparan los valores de cada municipio con respecto al estado para conocer las ramas pertenecientes al sector básico y al sector no básico del municipio.

Douglas North considera que, "para propósitos del análisis económico, el concepto de región podía ser definido en términos de su desarrollo alrededor de una base común de exportación" (cit. Gago, 1983:3). De manera precisa, el modelo de la base económica postula que las exportaciones de una localidad son la fuerza dinámica que produce un nuevo ingreso monetario, estimulando el crecimiento que sus industrias básicas requieren como servicios de soporte de la economía local. Por ello, "este modelo plantea que el crecimiento del sector exportador afecta la prosperidad de la economía local, quedando la expansión del sector residencial, o no básico, dependiente y pasivo del estímulo que produzca el crecimiento del sector básico" (Asuad, 2001:57).

Por consiguiente, un análisis complementario a los coeficientes de localización que determinan al sector básico y no básico es el cálculo del multiplicador de la base económica, que nos permite medir la magnitud de sus efectos sobre el consumo a nivel local. Morales (1999) ha propuesto formas de analizar la base económica de los estados al utilizar las ramas de 
producción municipal para el cálculo del multiplicador de la base económica, aludiendo que la importancia del sector básico radica en que permite la entrada de ingresos que sirven para fortalecer la economía local. "Así, el multiplicador con base en exportaciones es conceptualmente similar al multiplicador keynesiano, usado en el análisis macroeconómico" (Torres, 2009:197). El multiplicador tiene un efecto importante para las actividades básicas y no básicas locales, y de esta manera en el desarrollo regional. "Cuanto más diversificada e integrada sea la economía de la región, mayor será el multiplicador. Los agentes económicos (consumidores o empresas) tendrán mayores tendencias a gastar su dinero en la región si encuentran en ella los bienes y servicios que necesitan" (Polése,1998:156). De forma contraria, si el dinero se gasta en importaciones, éste se va fuera de la región y no servirá para generar ingresos o empleos en ella.

Aunado a lo anterior, los sectores ligados a las exportaciones son capaces de producir eslabonamientos, como efecto de la distribución del ingreso obtenido por la exportación. El gasto de dicho ingreso genera nuevas oportunidades de inversión en el mismo sector y en otros sectores de la economía local. Para Marshall (1920), al encontrarse esta dinámica en una misma localidad da como resultado las economías de aglomeración que producen externalidades positivas $y$, por consiguiente, economías externas debido a los rendimientos crecientes.

Al respecto, y con base en las ideas de Dussel (1999) sobre dinámica regional y competitividad, se sostiene que el análisis de la organización de redes productivas y de la integración directa de las localidades a los mercados interno y externo, mediante diferentes formas de encadenamientos mercantiles, es de gran importancia para el crecimiento económico de las regiones. Ya Hirschman (1981) lo había propuesto como eslabonamientos en la producción, donde los enlaces, vínculos o eslabonamientos hacia delante y hacia atrás surgen como una secuencia de características, más o menos imperativa, de decisiones de inversión que ocurren en el curso del desarrollo económico. Por lo que, la importancia de estos eslabonamientos se deriva de que las decisiones de inversión son relevantes, no sólo por su contribución inmediata a la producción sino también por el impulso que tales decisiones, probablemente, inspiran hacia nuevas inversiones a causa de sus eslabonamientos. 
Ahora, si se parte de la idea de que las regiones son "áreas definidas a partir del dominio territorial particular de una relación de acoplamiento" (Coraggio, 1989:90) es posible entender al contexto regional como un proceso dual de enriquecimiento y cambio estructural. La relación sectorregión es la representación de la estructura y el funcionamiento espacial de la economía, es decir, "suministra información sobre la asociación entre las actividades y el espacio, fundamentando así el dinamismo de los entes regionales y las relaciones sector-región como factores que facilitan que la región se convierta en sujeto de su propio desarrollo económico" (Dussel, 1999:72).

El estudio de la relación de la base económica de cada localidad con el exterior puede dar pautas para comprender la dinámica de las economías locales y el impacto de las exportaciones para la articulación de sistemas productivos. Cabe decir que uno de los aspectos que caracteriza la competencia es "la importancia de la cadena de producción, es decir, la competitividad depende de sus proveedores" (Asuad, 2001:14). En este sentido, Llisterri (2002) apunta que las regiones o localidades tradicionalmente retrasadas descubren nuevas oportunidades brindadas por sus ventajas competitivas, a la vez que son capaces de poner en valor su potencial endógeno y generar nuevas inversiones productivas más competitivas en la nueva situación de mercado. De esta manera las ventajas competitivas del territorio en su conjunto pueden redefinirse y pasar a ser de singular importancia para el desarrollo de cada entorno subregional.

La producción de las economías local y regional debe ser impulsada con procesos integrados y planificados con el afán de interrelacionar las actividades productivas para conformar sistemas productivos fuertes que permitan generar cadenas de agregación de valor - eslabonamientos productivos-. Al respecto, "es importante considerar que si el valor creado en la región es la medida de la riqueza que genera, la estrategia es la responsable de que ello suceda, por ser la que define dónde y cómo producir tal riqueza" (Ruíz, 2005:142); el diseño y ejecución de éste tipo de estrategias puede derivar en la generación de cadenas de valor que permitan, a través de la producción-exportación, elevar el nivel de bienestar de la población. 
Las cadenas de valor tienen estrecha relación con la empresa, sus proveedores, clientes y competidores, por lo que es necesario que las actividades de producción cuenten con estrategias para expandir sus potencialidades. De acuerdo con Yoguel (2005), este ambiente interconectado permite generar, en los sistemas de empresas, relaciones de tipo insumoproducto entre los agentes que forman parte de ellos; las cadenas productivas "están definidas a nivel del proceso de trabajo, como un conjunto de operaciones de producción encadenadas linealmente [...] unas proveen insumos necesarios para la producción realizada en otras" (Coraggio, 2004:39).

A grandes rasgos, la competitividad de una agrupación de unidades de producción - empresas-, localizadas en una región determinada, "consiste en su capacidad para mantener o incrementar su participación en la oferta de sus mercados de referencia y/o abrir nuevos mercados sirviéndole el incremento de la eficacia y eficiencia" (Fuentes, 2007:386). Para el desarrollo de la producción, donde los sistemas productivos son el eje rector, es inexorable la mejora en la productividad y calidad de los productos, tanto para el consumo interno como para la exportación.

En este sentido, la productividad es esencial para alcanzar la competitividad, aspecto importante para generar excedentes exportables. Alburquerque (1999) señala que antes de proponerse ser competitivos es primordial logar la productividad, pues solamente reforzando la estructura productiva local se pueden insertar los productos competitivamente en el mercado internacional. De la misma manera Canzanelli (2004) recomienda articular los elementos necesarios en la producción. Elementos como materia prima, insumos, tecnología, mano de obra calificada, servicios de apoyo, investigación e innovación que pueden ser abastecidos por unidades de producción — privadas o públicas - locales capaces de orientar la selección y gestión de nuevas tecnologías y técnicas de trabajo.

Al respecto, las reflexiones de Storper y Walker (1989) sugieren que los complejos territoriales promueven la integración de sistemas productivos de producción flexible donde estos sistemas no se limitan únicamente a aceptar la división del trabajo, sino que buscan dividirse los flujos de 
trabajo con vínculos de contratos y compromisos de producción que pueden lograr que las diferentes actividades que los componen evolucionen de manera continua. Las interconexiones en la esfera de la producción llevan a constituir cadenas de valor especializadas que faciliten la relación entre las empresas participantes en la cadena, además de elevar el ingreso real mejora las condiciones de vida y trabajo de los agentes que intervienen en el sistema productivo local-regional.

En definitiva, los sistemas productivos son un "modelo de organización de la producción a través de la división del trabajo entre las empresas y la creación de un sistema de intercambios [...] producen el aumento de la productividad y el crecimiento de la economía local" (Vázquez, 2002:39). A través de un sinnúmero de interconexiones productivas intrarregionales, y de los procesos manifiestos en ellas, surgen relaciones de cooperación y de competitividad. A medida que las interrelaciones se vuelven más sólidas mayor será el desarrollo de la localidad y la región.

Por consiguiente, resulta necesario valorar el carácter específico de la localidad, su forma concreta de funcionamiento, la singularidad de sus actividades y los procesos de interacción-articulación que se desarrollan tanto en su interior como con otras localidades, ya que, como lo señala Dicken (1993), se debe tender hacia lo local, pues este contexto es importante no sólo por sus características intrínsecas, sino también por sus relaciones con otros lugares y diferentes escalas geográficas. De ello la necesidad de identificar la articulación potencial entre actividades productivas de los municipios de Baja California Sur, considerando los efectos de la exportación de los excedentes de la producción de sus sectores económicos.

\section{METODOLOGÍA REGIONAL}

De acuerdo con lo anterior es importante presentar el área de estudio sujeto al análisis de los sistemas productivos a nivel municipal, así como el manejo de los datos, y una breve descripción de la aplicación del modelo de base económica y el multiplicador de la base. 


\section{1. Área de estudio}

Baja California Sur, BCS (mapa 1), es una entidad federativa localizada en el noroeste de México. Está conformada por cinco municipios: Comondú, Mulegé, La Paz, Los Cabos y Loreto. El estado ocupa un área de 73 922. 47, es decir, 3.77\% del territorio nacional. Al norte es limítrofe con el estado de Baja California, al este con el Mar de Cortés y al sur y oeste con el Océano Pacífico. Esta entidad federativa es de las menos habitadas del país con un registro de población de 637026 en 2010 y una densidad demográfica de 8.62 . En ese mismo año el PIB de Baja California Sur representó 0.63\% (53 098498 miles de pesos, a precios de 2003) de la producción nacional; poco más de $75 \%$ del PIB proviene de las actividades del sector terciario (INEGI, 2011).

La economía de BCS es estable y dinámica ya que, en 2008, logró colocarse en el octavo lugar de competitividad en el país. Con respecto al porcentaje de su PIB es el estado con mayor venta de inmuebles, el que presenta mayor productividad agropecuaria y es la segunda entidad, después del Distrito Federal, con mayor inversión extranjera. También es la entidad que registró mayor crecimiento real del PIB. Los sectores dedicados a las actividades relacionadas con los servicios y las manufacturas son los más competitivos, aportan, respectivamente, 78.6 y 16.3\% al PIB de la entidad (IMCO, 2008).

En 2010 Baja California Sur era un estado con bajo grado de marginación, en el ámbito nacional se situó en el lugar veintitrés; Guerrero y el Distrito Federal registraron los índices de marginación más alto y más bajo, respectivamente. En el contexto subbajacaliforniano, los municipios Comondú y Mulegé presentaron bajo nivel de marginación, mientras que La Paz, Los Cabos y Loreto eran municipios en condición de muy baja marginación. A grandes rasgos, en dicho año $79.6 \%$ de la población se encontraba en condición de baja marginalidad y el resto (20.4\%) en muy baja (CONAPO, 2010). 


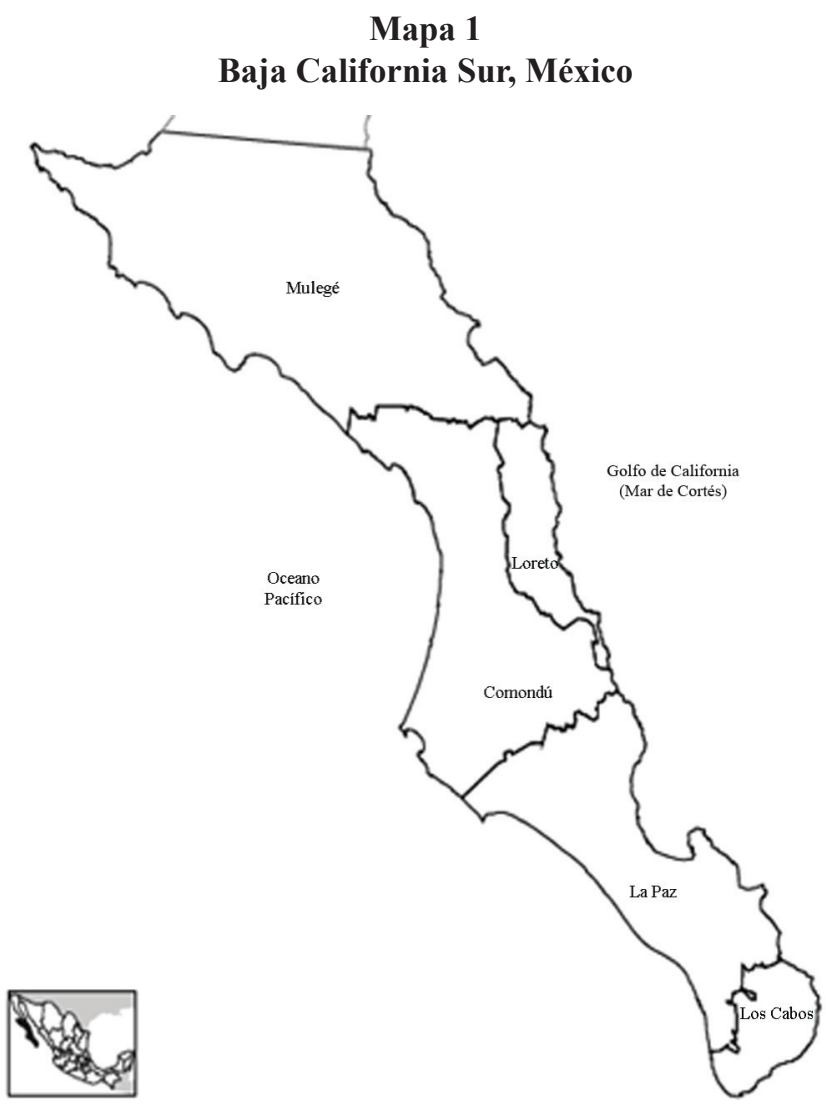

Fuente: adaptado de INEGI. Marco Geoestadístico Municipal 2005.

\subsection{Los datos}

Para el análisis de los efectos de las exportaciones en el crecimiento económico de BCS se consideran los cinco municipios que integran la entidad federativa.

Los datos cubren el año 2009, en el cual la variable valor agregado censal bruto - a precios corrientes- (VA) son estadísticas consultadas en el censo económico de 2009 publicado por el Instituto Nacional de Estadística y Geografía (INEGI). Las actividades productivas se agrupan en 17 sectores: agricultura, silvicultura, pesca y caza (1), minería (2), energía 
eléctrica, suministro de agua y de gas (3),construcción (4), industrias manufactureras (5), comercio (6), transportes, correos y almacenamiento (7), información en medios masivos (8), servicios financieros y de seguros (9), servicios inmobiliarios y de alquiler de bienes muebles e intangibles (10), servicios profesionales, científicos y técnicos (11), servicios de apoyo a los negocios y manejo de desechos y servicios de remediación (12), servicios educativos (13), servicios de salud y de asistencia social (14), servicios de esparcimiento (15), servicios de alojamiento temporal y de reparación de alimentos y bebidas (16) y otros servicios, excepto actividades gubernamentales (17).

La información se organiza en una matriz que representa los datos referidos al VA por sector (filas) y por municipio (columnas) (ver anexo I).

\subsection{El modelo de base económica y su multiplicador}

Sin duda alguna, un aspecto crucial en el análisis económico regional es la competitividad. El modelo de la base económica exportadora da cuenta de ello, pues indica que "el crecimiento económico regional es una función del rendimiento exportador regional" (Richardson, 1977:24), en otras palabras, muestra eventuales factores de competitividad al destacar la relevancia de la apertura de las economías locales — municipales-y el rol que desempeña la demanda exógena en el crecimiento regional.

De esta manera, el modelo de base económica puede ser expresada en términos del VA, de acuerdo con la siguiente notación (véase Boisier, 1980:61-71, Lira y Quiroga, 2009:24):

$$
\text { (1) } X_{i j}=V A_{i j}-\left(\frac{V A_{i j}}{Q_{i j}}\right) ; \text { para todos } \operatorname{los} Q_{i j}>1^{1}
$$

Lo que es igual a:

$$
\text { (2) } V A_{i j}-\left(\frac{V A_{i j}}{\frac{V A_{i j}}{\frac{\sum i V A_{i j}}{\sum j V A_{i j}}}}\right) ; \text { para todos } \operatorname{los} Q_{i j}>1
$$

$\overline{{ }^{1} \text { El cociente } \frac{V A_{i j}}{Q_{i j}}}$ expresa el consumo interno del municipio, bajo el supuesto de homogeneidad en el consumo, la tecnología y la productividad. 
Dónde:

$$
\text { (3) } X_{j}=\sum i V A_{i j}=V A B_{j}
$$

$i=$ Sector

$j=$ Municipio

$V A=$ Valor Agregado

$X_{i j}=$ Valor Agregado Básico o Exportable del Sector $i$ del Municipio $j$

$Q_{i j}=$ Sectores con Especialización Relativa o Producción Excedentaria en el Municipio

$X_{j}=$ Valor Agregado Básico (VAB) o Exportable del Municipio $j$

Cabe señalar que las remuneraciones por concepto de exportaciones (valor agregado básico) son distribuidas en los sectores locales con producción excedente, lo cual genera ingreso adicional a través del multiplicador de la base económica.

De ese modo, los sectores exportadores generan flujos de nueva riqueza hacia los municipios. Con la parte de esos ingresos gastados en el consumo local los sectores con especialización relativa están en condiciones de crear nuevos consumos en las actividades orientadas a la satisfacción de la demanda local. En otras palabras, las unidades de producción en condiciones de exportar gastan los ingresos generados en las actividades destinadas al consumo interno, lo cual repercute de manera positiva en la creación de más producción, lo que lleva consigo mayores beneficios para la población local.

Estos mayores beneficios que se generan por el hecho de exportar los excedentes de un sector de la economía local se pueden estimar a través de su multiplicador. De acuerdo con Mendoza y Díaz: "el tamaño del multiplicador depende de la propensión a gastar dinero en la economía local. Las actividades orientadas a satisfacer a los consumidores ubicados en los municipios pueden ser parte de la actividad exportadora y de las actividades básicas de la región" (2006:42). De esta forma, la producción excedente del municipio permite ingresar recursos adicionales que estimulan el consumo al interior del municipio.

Los términos para el cálculo del multiplicador municipal de la base económica son los siguientes:

(4) $V A T=V A B j+V A N B j$ 
Dónde:

$$
\text { (5) } M_{j}=1+p_{j}=\left(\frac{V A T}{V A B_{j}}\right)
$$

VAT $=$ Valor Agregado Total

$M_{j}=$ Multiplicador Municipal

$p_{j}=$ Impacto en el Valor Agregado Total de una unidad de Valor Agregado Básico

$V A B_{j}=$ VAlor Agregado Básico del Municipio

$V A N B_{j}=$ Valor Agregado No Básico del Municipio

Las ecuaciones 4 y 5 presentan las variables que determinan el ingreso municipal. Este multiplicador depende de la propensión marginal al consumo local y del ingreso generado por las actividades de exportación. La presencia de un sector productivo importante se manifiesta por ramas de productividad con multiplicadores significativos, mismos que propician polos de crecimiento. Dicha constatación sugiere un eventual encadenamiento de sectores en donde el crecimiento no precisamente aparece de manera uniforme entre las actividades productivas de las economías locales sino que se concentra en algunos sectores, según la concepción de polos de crecimiento de Perroux (1993). Estas actividades con relativo crecimiento tienden a formar sistemas productivos interconectándose con las actividades destinadas al consumo interno o no básico. El estudio de interdependencias requiere de otro tipo de técnicas, una de las herramientas adecuadas para el análisis de eslabonamientos productivos es el modelo insumo-producto (véase Burgess, 1968; Mariña, 1993; Fuentes, 2002; Callicó, Bouchain y Mariña, 2003).

El multiplicador de la base económica está compuesto por "la propensión a consumir localmente y sobre todo a consumir importaciones; si la tendencia a consumir localmente es más elevada, el multiplicador será mayor" (Mendoza y Díaz, 2006: 44) y viceversa.

En suma, la base económica exportable es un modelo útil para el análisis económico de una región determinada ya que vincula, de manera directa, sus actividades exportadoras con el resto de las economías locales que constituyen la región y mejora las posibilidades de crecimiento de la misma. Además, su cálculo es relativamente simple, ya que requiere de información contable, para un solo año, agregada por sectores de actividad económica de cada municipio y del resto de la entidad. 


\section{BAJA CALIFORNIA SUR, ESTUDIO DE CASO}

De acuerdo con la evidencia encontrada para el caso de Baja California Sur, 2009, es posible decir lo siguiente (ver anexo II): la economía del municipio de Comondú presenta un excedente de valor añadido para la satisfacción de la demanda externa; el sector con mayor peso en el municipio es el 8 (información en medios masivos), el cual aporta más del 60\% a la base económica; le siguen, en orden de relevancia, las actividades 5 (industrias manufactureras) y 1 (agricultura, ganadería, silvicultura, pesca y caza). De ello se infiere que las retribuciones monetarias por exportar la producción excedentaria del sector 8 explican, en mayor medida, la dinámica productiva de las actividades orientadas a cubrir la demanda del municipio, ya que las actividades situadas en este sector son las que tienden hacia la mayor interconexión con el resto de las actividades básicas y no básicas. Empero, el multiplicador municipal al presentar un valor de 2.11 evidencia que el ingreso percibido en los sectores con especialización para exportar no se destina en su totalidad para consumir lo producido en el municipio sino que también se adquieren productos de origen externo. Dichos resultados posicionan a este municipio con potencial para interconectar flujos de mercancías.

Por otro lado, es incuestionable que la base económica del municipio de Mulegé es sostenida por el valor agregado exportable de los sectores 1 (agricultura, ganadería, silvicultura, pesca y caza) y 5 (industrias manufactureras), ya que, en conjunto, colaboran con poco más de $90 \%$ del valor agregado básico municipal. La lectura del multiplicador obtenido sugiere alta propensión al consumo de importaciones; es decir, que por cada unidad de valor agregado producida en los sectores con producción excedente se generan 1.76 unidades de valor agregado en el conjunto de la economía municipal, hecho que ubica a esta economía local como la más débil para generar relaciones de insumo-producto en el estado.

En turno, las exportaciones del municipio de La Paz se solventan con $81 \%$ del valor agregado excedentario generado en sus sectores 3 (energía eléctrica, suministro de agua y de gas) y 6 (comercio); por lo que tales sectores son los más competitivos en ésta economía. Los flujos de la riqueza generada por la venta de productos fuera del municipio están en 
condiciones de ser gastados en el consumo de bienes y servicios ofertados por las empresas locales; acontecimiento que tiene repercusiones positivas sobre las ganancias de los establecimientos encargados de abastecer al mercado interno. A su vez, el cálculo del multiplicador muestra que La Paz es uno de los municipios subbajacalifornianos con mejores condiciones para interconectar sus actividades exportadoras con las actividades que atienden la demanda endógena.

Por su parte, la economía de Los Cabos es la que registra mayor cantidad de valor agregado exportable y representa poco menos de $45 \%$ de la base económica (valor agregado bruto) de Baja California Sur (ver anexo 1). Poco más de $70 \%$ de la producción exportable proviene de las diferentes actividades que conforman el sector 16 (servicios de alojamiento y preparación de alimentos). Este sector, al ser el de mayor peso relativo entre las actividades especializadas para la exportación, es el que presenta mejores condiciones para articular relaciones cliente-proveedor, ya que la mayoría de los sectores, hipotéticamente, encausan sus esfuerzos a cubrir las necesidades locales; esto es, las actividades dedicadas al alojamiento y preparación de alimentos tienen fuerte potencial para articular un sistema productivo sólido basado en los ingresos derivados de las exportaciones de su valor agregado excedente.

Finalmente, Loreto presenta una base económica (valor agregado bruto) poco significativa con respecto a la economía estatal (ver anexo 1), apenas representa $1 \%$ del valor agregado susceptible de ser exportado, por lo que se le puede considerar como un municipio poco competitivo respecto de los otros. Sin embargo, el multiplicador municipal es el más alto (5.8) de la economía subbajacaliforniana; lo cual significa que por cada unidad de valor añadido en los sectores básicos se crean 5.8 unidades de valor agregado en la economía local, lo que tiene efectos positivos sobre los sectores no básicos. Esta última situación coloca al municipio con el más alto potencial en la entidad para articular un sistema de intercambios entre los sectores básicos y los no básicos.

Los resultados son evidencia de que la economía del estado de Baja California Sur, en general, es competitiva pues todos los municipios presentan excedentes de valor agregado o exportable. Las economías locales parecen estar en condiciones de atender el consumo endógeno, dependiendo 
en menor medida de importaciones provenientes de los otros municipios, del resto del país o del mundo; lo que conduce hacia mayores beneficios para las empresas locales.

Las relaciones de proveeduría entre sectores económicos presentan indicios favorables para conformar sistemas de producción local-regional para competir en los contextos inter e intrarregionales.

Como ya se mencionó, todos los municipios de BCS presentan algún potencial para articular sistemas de producción, por lo que es útil presentar un diagnóstico que permita ubicar, aunque sea de manera mínima, las características sectoriales que permiten articular intercambios comerciales. En el cuadro 1 se muestra una clasificación de los sectores básicos y no básicos de los municipios subbajacalifornianos. En general, y de acuerdo con la base económica de valor agregado exportable, se presenta en la entidad una concentración marcada hacia sectores dedicados a los servicios, comportamiento que hace vulnerable a la economía regional frente cambios ocurridos en las economías externas. Ante la posibilidad de distorsiones en la demanda exógena es necesario pensar en una ruta que canalice, de manera eficiente, el capital proveniente de las exportaciones hacia inversiones en los sectores enfocados al abasto de los sistemas económicos de tipo local así como a los otros sectores básicos. Por ello es necesario plantear políticas de desarrollo local-regional integrales.

\section{CUADRO 1}

Clasificación de los sectores de Baja California Sur

\begin{tabular}{|c|c|c|}
\hline & \multicolumn{2}{|c|}{ Sectores } \\
\hline Municipio & No básico & Básico \\
\hline Comondú & $\begin{array}{l}\text { (2) minería, (3) energía eléctrica, su- } \\
\text { ministro de agua y de gas, (4) cons- } \\
\text { trucción, (7) transportes, correos y } \\
\text { almacenamiento, (10) servicios inmo- } \\
\text { biliarios y de alquiler, (11) servicios } \\
\text { profesionales, científicos y técnicos, } \\
\text { (12) servicios a negocios, manejo de } \\
\text { desechos y de remediación, (14) ser- } \\
\text { vicios de salud y de asistencia social, } \\
\text { (15) servicios de esparcimiento, (16) } \\
\text { otros servicios excepto actividades } \\
\text { gubernamentales }\end{array}$ & $\begin{array}{l}\text { (1) agricultura, ganadería, silvicultura, } \\
\text { pesca y caza, (5) industrias manufactu- } \\
\text { reras, (6) comercio, (8) información en } \\
\text { medios masivos, (9) servicios financieros } \\
\text { y de seguros, (13) servicios educativos, } \\
\text { (17) otros servicios excepto actividades } \\
\text { gubernamentales }\end{array}$ \\
\hline
\end{tabular}




\begin{tabular}{|c|c|c|}
\hline Mulegé & $\begin{array}{l}\text { (3) energía eléctrica, suministro de } \\
\text { agua y de gas, (4) construcción, (6) } \\
\text { comercio, (8) información en medios } \\
\text { masivos, (10) servicios inmobiliarios } \\
\text { y de alquiler, (11) servicios profe- } \\
\text { sionales, científicos y técnicos, (12) } \\
\text { servicios a negocios, manejo de dese- } \\
\text { chos y de remediación, (13) servicios } \\
\text { educativos, (14) servicios de salud y } \\
\text { de asistencia social, (15) servicios de } \\
\text { esparcimiento, (16) otros servicios } \\
\text { excepto actividades gubernamentales, } \\
\text { (17) otros servicios excepto activida- } \\
\text { des gubernamentales }\end{array}$ & $\begin{array}{l}\text { (1) agricultura, ganadería, silvicultura, } \\
\text { pesca y caza, (2) minería, (5) industrias } \\
\text { manufactureras, (7) transportes, correos y } \\
\text { almacenamiento, (9) servicios financie- } \\
\text { ros y de seguros }\end{array}$ \\
\hline $\mathrm{La} \mathrm{Paz}$ & $\begin{array}{l}\text { (1) agricultura, ganadería, silvicultu- } \\
\text { ra, pesca y caza, (8) información en } \\
\text { medios masivos, (10) servicios inmo- } \\
\text { biliarios y de alquiler, (12) servicios a } \\
\text { negocios, manejo de desechos y de re- } \\
\text { mediación, (13) servicios educativos, } \\
\text { (15) servicios de esparcimiento, (16) } \\
\text { otros servicios excepto actividades } \\
\text { gubernamentales }\end{array}$ & $\begin{array}{l}\text { (2) minería, (3) energía eléctrica, suminis- } \\
\text { tro de agua y de gas, (4) construcción, (5) } \\
\text { industrias manufactureras, (6) comercio, } \\
\text { (7) transportes, correos y almacenamien- } \\
\text { to, (9) servicios financieros y de seguros, } \\
\text { (11) servicios profesionales, científicos y } \\
\text { técnicos, (14) servicios de salud y de asis- } \\
\text { tencia social, (17) otros servicios excepto } \\
\text { actividades gubernamentales }\end{array}$ \\
\hline Los Cabos & $\begin{array}{l}\text { (1) agricultura, ganadería, silvicultura, } \\
\text { pesca y caza, (2) minería, (3) energía } \\
\text { eléctrica, suministro de agua y de gas, } \\
\text { (4) construcción, (5) industrias ma- } \\
\text { nufactureras, (6) comercio, (7) trans- } \\
\text { portes, correos y almacenamiento, (8) } \\
\text { información en medios masivos, (9) } \\
\text { servicios financieros y de seguros, } \\
\text { (17) otros servicios excepto activida- } \\
\text { des gubernamentales }\end{array}$ & $\begin{array}{l}\text { (10) servicios inmobiliarios y de alquiler, } \\
\text { (11) servicios profesionales, científicos y } \\
\text { técnicos, (12) servicios a negocios, ma- } \\
\text { nejo de desechos y de remediación, (13) } \\
\text { servicios educativos, (14) servicios de } \\
\text { salud y de asistencia social, (15) servicios } \\
\text { de esparcimiento, (16) otros servicios ex- } \\
\text { cepto actividades gubernamentales }\end{array}$ \\
\hline Loreto & $\begin{array}{l}\text { (2) minería, (5) industrias manufactu- } \\
\text { reras, (8) información en medios masi- } \\
\text { vos, (10) servicios inmobiliarios y de } \\
\text { alquiler, (11) servicios profesionales, } \\
\text { científicos y técnicos, (12) servicios a } \\
\text { negocios, manejo de desechos y de re- } \\
\text { mediación, (13) servicios educativos, } \\
\text { (14) servicios de salud y de asistencia } \\
\text { social, (15) servicios de esparcimien- } \\
\text { to, (16) otros servicios excepto activi- } \\
\text { dades gubernamentales }\end{array}$ & $\begin{array}{l}\text { (1) agricultura, ganadería, silvicultura, } \\
\text { pesca y caza, (3) energía eléctrica, sumi- } \\
\text { nistro de agua y de gas, (4) construcción, } \\
\text { (6) comercio, (7) transportes, correos y } \\
\text { almacenamiento, (9) servicios financieros } \\
\text { y de seguros, (17) otros servicios excepto } \\
\text { actividades gubernamentales }\end{array}$ \\
\hline
\end{tabular}

Fuente: Elaboración propia con base en la información del anexo II. 


\section{COMENTARIOS FINALES}

Existen sistemas de interconexiones entre las actividades locales en Baja California Sur para el año 2009 que muestran los beneficios internos como resultado de la demanda exógena del valor agregado excedente en las economías municipales.

El crecimiento económico subbajacaliforniano debe basarse en un enfoque de competitividad de sus sistemas productivos locales. Entorno a éstos se presentan cuatro propuestas:

(i) Diseñar estrategias para el fomento de sistemas productivos con el afán de competir de mejor manera en los mercados externos,

(ii) Organizar la producción de manera que se propicie la innovación y la transferencia de tecnología para el desarrollo local,

(iii) Considerar a la base económica como un factor que propicia mejores condiciones para la competitividad de economías intrarregionales,

(iv) Incrementar la producción más allá de la satisfacción del consumo endógeno, con el objetivo de generar mayor dinamismo en el crecimiento económico de los municipios.

Si se parte de los recursos disponibles en la región, en el sentido que Fuentes (2007) plantea, es posible vislumbrar políticas públicas que centren su prioridad en la capacidad competitiva de las localidades y fijar como objetivos primordiales: el desarrollo de los sistemas productivos, el aumento de empleo y del ingreso y, claro está, el mejoramiento en los niveles y calidad de vida de los habitantes en el estado.

Además, la competitividad de la economía de Baja California Sur debe sustentarse en la participación pro-activa del desempeño de diferentes actores como los son las empresas, la universidad y el gobierno, entre otros, para crear condiciones necesarias desde un enfoque no coyuntural sino sistémico y estructural. Desde esta perspectiva, y con base en el 
aporte teórico de Meyer (2005) y empírico de Woo (2002), la estructura de la competitividad de la economía subbajacaliforniana debe ser integrada desde los niveles micro de las redes de empresas; del nivel meso, que corresponde a la eficiencia de políticas específicas orientadas a los sectores de actividad más dinámica y desarrollo de instituciones, y el macro nivel, relativo a las condiciones macroeconómicas nacionales e internacionales. Las estrategias para el desarrollo local y regional de acuerdo con Silva (2003:57) “[...] tienen que estar basadas en una gestión asociativa entre representantes públicos y privados". Los elementos que acompañan a la competitividad sistémica y estructural pueden ser, con los esfuerzos coordinados de los diferentes agentes del desarrollo, el soporte de un modelo de desarrollo económico que tenga por objetivo rector elevar la productividad y calidad de los bienes y servicios ofertados por las diferentes empresas de los municipios de Baja California Sur. Los diferentes niveles de gobierno deben sumar esfuerzos para instrumentar políticas y programas que generen un entorno favorable, empresarial y social, para alcanzar un modelo de desarrollo basado en sus potencialidades endógenas que derive en mejores beneficios para los habitantes en la entidad. 


\section{BIBLIOGRAFÍA}

Alburquerque, F. 1999. Desarrollo económico local en Europa y América Latina, Consejo Superior de Investigaciones Científicas, España.

Asuad, N. 2001. Economía regional y urbana, BUAP/Colegio de Puebla/ AEFEUNAM, México.

Boisier, S. 1993. "La articulación estado-región. Clave del desarrollo regional", en H. Ávila (comp.) Lecturas de análisis regional en México y América Latina, pp. 309-335, UACH, México.

------. 1980. Técnicas de análisis regional con información limitada, Cuadernos del ILPES, 27, Chile.

Burgess, C. 1968. Input-output analysis and resource allocation, Cambridge University Press, Gran Bretaña.

Callicó, J., R. Bouchain y A. Mariña. 2003. Insumo-producto regional y otras aplicaciones, UAM/ UNAM/UDG, México.

Canzanelli, G. 2004. Valoración del potencial endógeno, competitividad territorial y lucha contra la pobreza, CIRCLE, Paper No.1.

Consejo Nacional de Población (CONAPO). 2010. Índice de marginación por entidad federativa y municipio, en http://conapo.gob.mx.

Coraggio, J. 2004. La gente o el capital. Desarrollo local y economía del trabajo, Espacio Editorial, Argentina.

------. 1989. "Sobre la espacialidad social y el concepto de región". Coraggio, J., F. Sabaté y O. Colman (comps.), La cuestión regional en América Latina, pp. 67-105, Ediciones Ciudad, Ecuador.

Dicken, P. 1993. Globalization processes and local economies, Conference of Globalization and the North America Free Trade Impact on Rural Communities, The Aspen Institute Mimeo.

Dussel, E. 1999. "Reflexiones sobre concepto y experiencias internacionales de industrialización regional”, en C. Duran y E. Dussel (comps.) Dinámica regional y competitividad industrial, pp. 5777, UNAM/FFE/JUS, México.

Fuentes, N. 2002. Matrices de insumo-producto de los estados fronterizos del norte de México, UABC/Plaza y Valdés, México.

-------. 2007. "Sistemas locales y la competitividad de las relaciones industriales. La experiencia de Baja California”, en J. Jardón (comp.) 
Evolucionismo económico, instituciones y sistemas complejos adaptativos, pp. 385-406, Porrúa, México.

Gago, A. 1983. Crecimiento económico regional, organización espacial y desequilibrio espacial: un análisis teórico, UNSJ, Argentina.

Hirschman A. 1981. La estrategia del desarrollo económico, FCE, México.

Iglesias, D. y J. Ramírez. 2008. "La formación de sistemas productivos locales”, Teoría y Praxis, núm. 5.

Instituto Mexicano para la Competitividad A.C. (IMCO). 2008. Índice de competitividad estatal 2008: aspiraciones y realidad, México.

Instituto Nacional de Estadística y Geografía (INEGI). México en Cifras 2011, México. Consultado en http://www.inegi.org.mx/

-----. internet Censo Económico 2009, México. Consultado en http:// www.inegi.org.mx/

------. Marco Geoestadístico Municipal 2005, México. Consultado en http://www.inegi.org.mx/

Lira, L. y B. Quiroga. 2009. Técnicas de análisis regional, Serie Manuales, 59, ILPES, Chile.

Llisterri, J. 2002. "Competitividad en el territorio y desarrollo económico local", Mercado de Valores, núm. 3, México.

Marshall, A. 1920. Principles of Economics, 8 a edición, Macmillan, Londres.

Massey, D. s/f. Problemas actuales de los estudios regionales, en T. Caprano, La cuestión regional y los recursos naturales, UACh, México Mariña, A. 1993. Insumo-producto: aplicaciones básicas al análisis económico estructural, UAM, México.

Mendoza J. y A. Díaz Bautista. 2006. Economía regional moderna. Teoría y práctica. COLEF/UG/Plaza y Valdés, México.

Meyer-Stamer, J. 2005. "Estrategias de desarrollo local/regional: cluster, políticas de ubicación y competitividad sistémica", en A. Solari y J. Martínez (comps.), Desarrollo local, textos cardinales, UMSNH, México.

Morales, F. 1999. Manual de diagnóstico económico municipal. Sistema de indicadores regionales (SIR), Red de Información Municipal (RIM-CESEM), México. 
Perroux, F. 1993. "Notas sobre el concepto polos de crecimiento", en H. Ávila (comp.) Lecturas de análisis regional en México y América Latina, Universidad Autónoma de Chapingo, México.

Polése, M. 1998. Economía urbana y regional. Introducción a la relación entre territorio y desarrollo, LUR, BUAP, GIM, Costa Rica.

Richardson, H. 1977. Teoría del crecimiento regional, Ediciones Pirámide, España.

Ruíz, C. 2005. Dimensión territorial del desarrollo económico de México, UNAM, México.

Silva, I. 2003. Disparidades, competitividad territorial y desarrollo local y regional en América Latina,Serie Gestión Pública, núm. 33, ILPES, Chile.

Storper M. y R. Walker R. 1989. The capitalism imperative: territory, technology and industrial growth, Blackwell, Oxford.

Torres Torres, F. (Coordinador). 2009. Técnicas para el análisis regional. Desarrollo y aplicaciones. UNAM, Instituto de Investigaciones Económicas, Editorial Trillas, México.

Yoguel, G. 2005. Creación de competencias en ambientes locales y redes productivas, en A. Solari y J. Martínez (comps.) Desarrollo local, textos cardinales, MSNH, México.

Vázquez Barquero, A. 2002. Las nuevas fuerzas del desarrollo, UAMAntoni Bosch, España.

Woo, G. 2002. "La gestión del desarrollo económico local. Apuntes desde la experiencia en el estado de Jalisco", El Mercado de Valores, núm. 3, pp.28-36. 




Revista de Economía - Vol. XXX - Núm. 80 


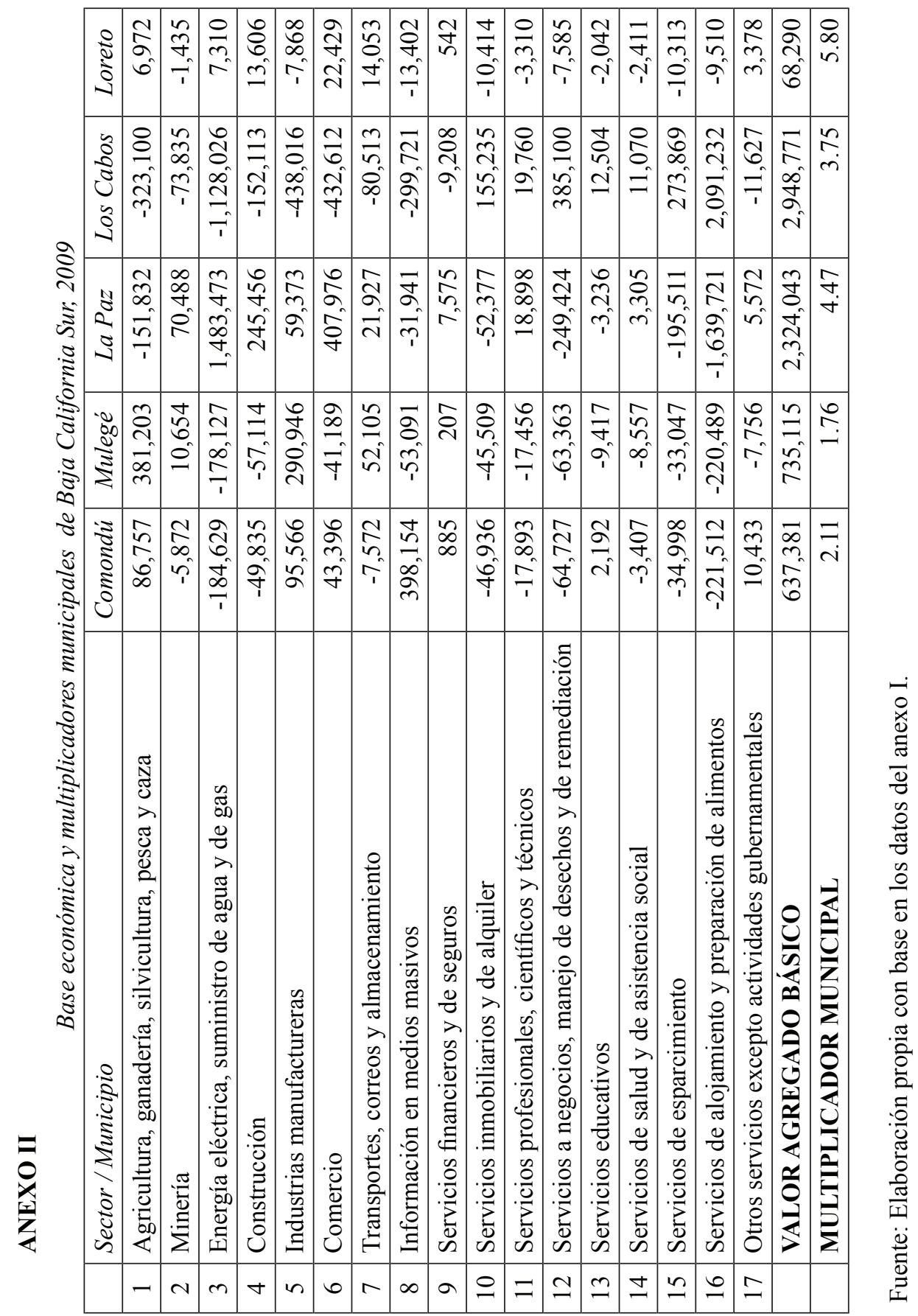

Enero a Junio de 2013 - Págs: 9-33 